\section{Endacrinalagia \\ A METODOLOGIA PROBE PODE SER CONSIDERADA UMA ALTERNATIVA AOS ESTUDOS RANDOMIZADOS DUPLO-CEGOS?}

A aprovação regulatória de novos medicamentos usualmente requer estudos clínicos randomizados, adequadamente desenhados e bem conduzidos. 0 mascaramento (duplo-cego) é um dos princípios fundamentais para se evitar o viés na pesquisa, já que tanto pesquisadores como participantes de pesquisa podem ter noções preconcebidas, assim como esperanças e expectativas de que novas intervenções sejam mais benéficas que as antigas ou que o placebo ${ }^{1}$.

Embora os estudos clínicos randomizados duplo-cegos sejam considerados ideais, principalmente na fase III de desenvolvimento, este paradigma pode distorcer um dos objetivos fundamentais destes estudos que é comparar um novo regime terapêutico com o padrão, sob condições clínicas reais. E isto se torna especialmente problemático quando o tratamento considerado padrão exige exames regulares de monitoramento de segurança e/ou ajuste de doses $^{2}$. Neste contexto, algumas desvantagens do desenho duplocego emergem: (a) A complexidade da administração de droga em esquema duplo-cego pode limitar a seleção de pacientes, com consequente efeito na validade externa do estudo; (b) A avaliação de eficácia e segurança pode ser comprometida por alterações na conduta clínica de rotina, introduzindo erros sistemáticos na avaliação das taxas de eventos ou desfechos; (c) Limitação a um único comparador, enquanto várias drogas comparáveis são freqüentemente utilizadas na prática clínica; (d) A avaliação clínica de pacientes com eventos/desfechos suspeitos podem levar à quebra do código de cegamento, eliminando parcialmente as vantagens deste desenho; (e) Os resultados com o tratamento comparador nem sempre são representativos da rotina clínica, uma vez que a intensidade do monitoramento nos estudos clínicos randomizados é geralmente mais rigorosaque no acompanhamento clínico habitual.

A alternativa pode estar nos estudos controlados abertos, mas que podem, entretanto, ser muito custosos à sociedade se os achados do estudo forem enviesados e conduzirem à introdução no mercado de tratamentos ineficazes e/ou inseguros ${ }^{1}$. Como evitar, portanto, o viés quando o mascaramento não é possível? Uma opção é o assim chamado desenho PROBE (Prospective, Randomized, Open, Blinded Endpoint). Neste desenho aberto incluem-se salvaguardas para evitar potenciais vieses, isto é, utiliza-se o mascaramento de todos os desfechos que devem ser, adicionalmente, objetivos, claramente definidos e clinicamente relevantes ${ }^{3}$. Estes desfechos devem ser avaliados por um comitê de adjudicação cego. Para assegurar que todos os eventos sejam capturados, deve haver uma revisão de todas as hospitalizações, de eventos sugerindo perda de função neurológica ou indicadores de sangramento como, por exemplo, diminuição dos níveis de hemoglobina. Instruçõesclaras devem ser dadas aos pacientes participantes e médicos para que contatem os responsáveis pelo estudo, caso sinais e sintomas sugiram algum dos desfechos. O relato de eventos deve ser "limpo" para assegurar a remoção de qualquer informação que revele o tratamento ao qual o paciente foi designado². 0 estudo é aberto com relação ao braço de tratamento, mas os investigadores, os membros do centro de pesquisa, do comitê científico, do comitê de adjudicação de eventos e o patrocinador permanecem cegos. Somente o DSMB (Data Safety Monitoring Board, ou comitê de segurança) tem acesso ao código de randomização e às taxas de eventos observadas em cada tratamento.

O viés no relato, na coleta, na avaliação e na classificação dos dados é, certamente, uma das maiores ameaças à validade de estudos clínicos randomizados; por outro lado, algumas condutas exigidas em estudos clínicos randomizados duplocegos podem comprometer a generalização de seus resultados ${ }^{2}$. Com adequado controle para minimizar o viés, estudos abertos fase III podem prover avaliação tão ou mais acurada do que estudos duplo-cegos, na medida em que eles se espelham na prática clínica usual. As medidas para minimizar os vieses são factíveis e podem assegurar a qualidade e validade deste tipo de estudo. Estudos publicados que usaram estes conceitos foram: CARE-HF (2005), CIBIS III (2005), ASCOT (2006) e, mais recentemente, o RE-LY (2009).

Sonia Mansoldo Dainesi

Doutoranda na Faculdade de Medicina da USP;

Diretora Médica da Boehringer Ingelheim do Brasil, São Paulo,SP

\section{Correspondência:}

Rua Ribeiro Lisboa 165

Morumbi - São Paulo - SP

\section{Referências}

1. Furberg CD and Soliman EZ. Double-blindness protects scientific validity. J Thromb Haemost. 2007;6:230-31.

2. Büller HR, Halperin JL, Bounameaux H, Prins M. Double-blind studies are not always optimum for evaluation of a novel therapy: the case of new anticoagulants. J Thromb Haemost. 2007;6:227-9.

3. Ezekowitz MD, Connolly S, Parekh A, Reilly PA, Varrone J, Wang S, et al. Rationale and design of RE-LY: Randomized evaluation of long-term anticoagulant therapy, warfarin, compared with dabigatran. Am Heart J. 2009;157: 805-10.e 2 